\title{
Using Microseismic Data Recorded at the Weyburn CCS-EOR Site to Assess the Likelihood of Induced Seismic Activity
}

James P. Verdon ${ }^{\mathrm{a}, \mathrm{b}^{*}}$

a. School of Earth Sciences, University of Bristol, Wills Memorial Building, Queen's Road, Bristol, U.K., BS8 1RJ.

b. Outer Limits Geophysics LLP, 608 Malt House, East Tucker Street, Bristol, U.K., BS1 $6 L Q$

* Corresponding Author. Email: James.Verdon@bristol.ac.uk, Tel: 0044117331 5135 .

Keywords: CCS, Induced Seismicity, Geomechanics, Passive seismic monitoring 


\begin{abstract}
Since 2000, $\mathrm{CO}_{2}$ has been successfully injected for the purposes of both enhanced oil recovery (EOR) and carbon capture and storage (CCS) at the Weyburn oilfield. A component of the geophysical monitoring program at Weyburn has included the use of downhole geophones to monitor microseismic activity. Microseismic events have already been used to assess the likelihood of $\mathrm{CO}_{2}$ leakage through the caprock at Weyburn. However, in recent years, the focus with respect to CCS and geomechanics has shifted to the concern that fluid injection will trigger induced seismicity. Therefore, in this paper we reanalyse the microseismic observations at Weyburn with respect to concerns regarding induced seismicity. We assess the population statistics of the Weyburn microseismic events, both in terms of the Gutenberg-Richter b-values and the correlation between moment release and injection/production volumes. Our observations serve to corroborate previous studies that considered the geomechanical cause of the microseismic events: namely that the events are not directly triggered by fluid injection, but in response to stress transfer through the rock frame in response to both production and injection. We observe that the b-value at Weyburn is close to 1 , the value expected for stress-driven, tectonic seismicity, and significantly lower than values observed in cases where the microseismicity is directly driven by fluid injection (during hydraulic fracturing, for example). We also note little to no correlation between fluid volume changes and induced seismicity - either injection volume alone or net volume change (produced - injected). Finally, we use the observed event statistics to forecast the likelihood that current operations at Weyburn will lead to larger events of sufficient magnitude to be of concern to local populations. We find that the probability of inducing such events is very unlikely.
\end{abstract}




\section{INTRODUCTION}

In 2000, the Weyburn oilfield, southeast Saskatchewan, began injecting $\mathrm{CO}_{2}$ for the purposes of Enhanced Oil Recovery (EOR). Alongside this commercial operation, a research project was developed to study the response of the site in terms of carbon capture and storage (CCS). As part of this project, a downhole geophone array was installed to detect and locate microseismic events induced by $\mathrm{CO}_{2}$ injection. The primary focus was on imaging fracture pathways that might be created by pressure increases in the reservoir, thereby addressing the concern that fracturing could create a leakage pathway through the sealing caprock (Verdon et al., 2011).

However, in recent years focus has shifted to concerns that $\mathrm{CO}_{2}$ injection will lead to injection-induced seismicity (e.g. Zoback and Gorelick, 2012; Verdon et al., 2013a). This shift in focus has been driven by the notable increase in the number of earthquakes induced by wastewater disposal in the mid-continental USA (Ellsworth, 2013), which has seen Oklahoma overtake California in the number of earthquakes per unit area in 2014 (Keranen et al., 2014).

A number of methods have been proposed that use microseismic events to assess the likelihood that injection processes will induce larger seismic events. These include: calculating the cumulative seismic moment released as a function of the volume injected, and extrapolating this forward to the expected final injection volume (e.g., Hallo et al., 2014; Verdon et al., 2015a); making an assessment of the seismogenic index (e.g., Shapiro et al., 2010; Dinske and Shapiro, 2013); scaling earthquake magnitudes with the size of the stimulated volume as demarcated by the microseismic event cloud (e.g., Shapiro et al., 2011); and using microseismic observations to calibrate geomechanical and structural models, from which induced seismicity is simulated numerically (e.g., Verdon et al., 2015b).

In this paper, our aim is to re-evaluate the microseismic data presented by Verdon et al. (2011). Verdon et al. (2011) considered the microseismicity primarily within the framework of leakage risk posed by the events; in this paper we use it to assess the likelihood that $\mathrm{CO}_{2}$ injection will trigger higher levels of seismic activity in the Weyburn oilfield.

\section{Microseismic Data Recorded at Weyburn}

\subsection{A brief description of the Weyburn oilfield}

The Weyburn oilfield is situated in the Williston Basin, southeast Saskatchewan. The hydrocarbon-bearing units are found in Carboniferous-age formations at depths of 1300- 
$1500 \mathrm{~m}$, specifically the Midale carbonates, which are divided into an upper, Marly layer, and a lower Vuggy layer. The primary caprock for these units is the overlying Midale evaporate. A second important seal is the Mesozoic Lower Watrous Shale, which in this area lies unconformably on top of the Carboniferous beds.

It is estimated that the Weyburn reservoir initially held 1.4 billion barrels of oil. Production began in 1954, and was initially unsupported, but from the 1960s onwards, water was reinjected to maintain pressures and to force oil towards the production wells. Production peaked after the waterflooding at 46,000 barrels/day. In 1991 the operator began the drilling of horizontal wells to target the less-permeable Marly layer. Before $\mathrm{CO}_{2}$ injection began, approximately $25 \%$ of the original oil in place had been produced. In $2000, \mathrm{CO}_{2}$ injection for EOR was initiated in the Phase 1A area of the field, followed by the Phase 1B area in 2003. It is estimated that the $\mathrm{CO}_{2}$-EOR will increase production by a further 130 million barrels ( $\sim 10 \%$ of the original oil in place). A full description of the Weyburn reservoir, and the $\mathrm{CO}_{2}$ injection operations conducted therein, can be found in Hitchon (2012).

\subsection{Microseismic monitoring at Weyburn}

In 2003 a microseismic array was installed to monitor a portion of the $\mathrm{CO}_{2}$ flood in the Phase 1B portion of the field. The monitoring array consisted of 8 triaxial geophones cemented into a disused vertical well, at depths of $1181-1356 \mathrm{~m}$, with a spacing of $25 \mathrm{~m}$. These depths place the geophones approximately $75-250 \mathrm{~m}$ above the reservoir. Apart from occasional pauses due to technical issues, these geophones recorded continuously from August 2003, 5 months before the start of $\mathrm{CO}_{2}$ injection in the nearest well to the microseismic monitoring well. Data is available until November 2010, shortly after when this same injection well was shut in.

The recorded data was processed on a monthly basis by a contractor, Engineering Seismology Group Ltd., of Ontario (Maxwell et al., 2005). The initial processing consisted of a triggering algorithm to search the data for possible events. Where triggers were detected, P- and S-wave phases were picked, and travel times inverted for the best-fit location, using a velocity model derived from a sonic log. The frequency spectra of the arriving phases were used to determine event magnitudes. With only a single downhole array, the array aperture is not sufficient to allow event source mechanisms to be determined.

Figure 1 shows the locations of injection and production wells in the vicinity of the monitoring array (M-1). In this area water and $\mathrm{CO}_{2}$ are injected in a WAG (WaterAlternating-Gas) injection procedure via vertical wells, while oil is produced from horizontal wells that trend NE-SW. Figure 2 shows monthly injection rates for water and $\mathrm{CO}_{2}$ through the WAG injection well nearest to the monitoring well (labelled I-1 in Figure 1), and the 
combined production rates from all of the surrounding oil wells (P-1 - P-7). $\mathrm{CO}_{2}$ injection rates are provided by the operator in standard units: in Figure 2 we convert these volumes into a volume at reservoir conditions by approximating the density of supercritical $\mathrm{CO}_{2}$ as $700 \mathrm{kgm}^{-3}$, in order to facilitate a comparison between injected and produced volumes of oil, water and $\mathrm{CO}_{2}$.

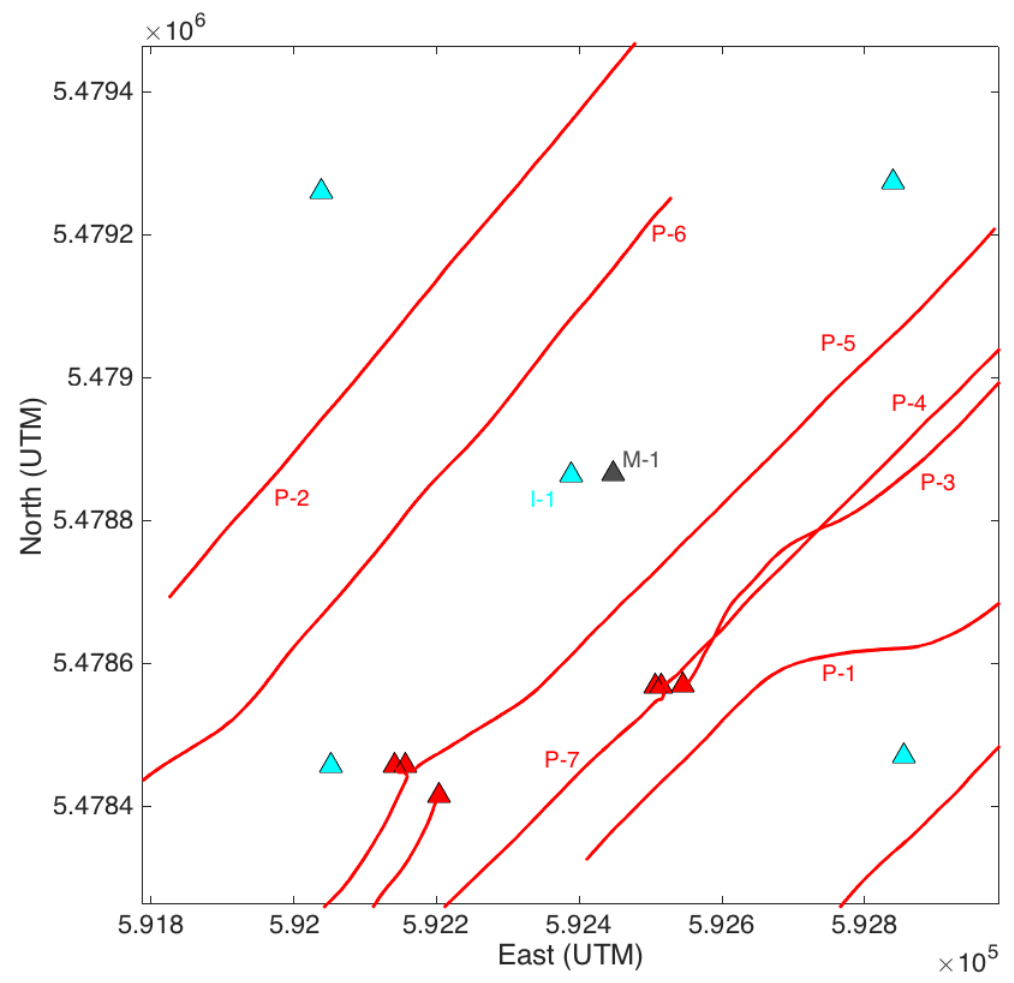

(a)

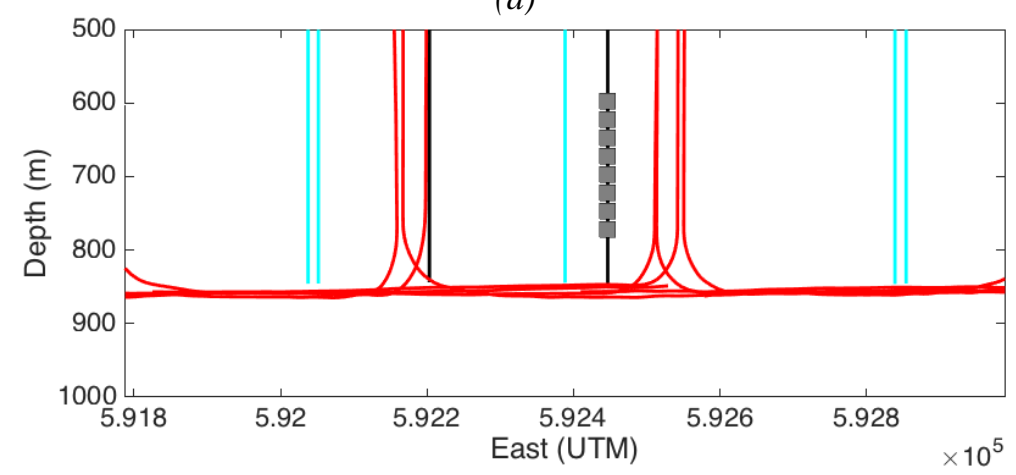

(b)

Figure 1: Map (a) and cross section (b) of the microseismic monitoring setup installed at Weyburn. Red lines and triangles show oil producers, blue lines and triangles show WAG injection wells. The microseismic monitoring well is labelled M-1 in the upper panel, while the monitoring geophone depths are shown by the grey squares in the lower panel. Depths are below sea level (the ground surface is approximately $580 \mathrm{~m}$ above sea level). 


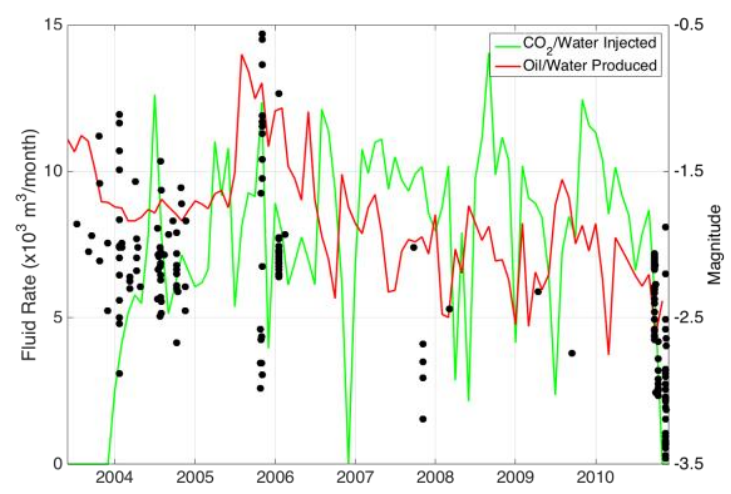

(a)

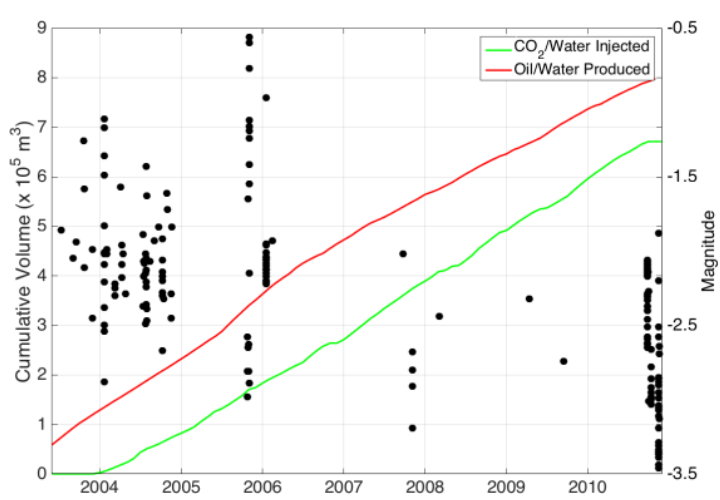

(b)

Figure 2: Panel (a) shows monthly injection rates (green) and production rates (red) for the wells near to the microseismic monitoring well, while (b) shows cumulative injection and production volumes. Also shown are the microseismic event occurrence times and magnitudes (black dots).

\subsection{Detected Events}

Over the full monitoring period (2003 - 2010), a total of 207 microseismic events were identified. The largest event had a magnitude of -0.5 , while the smallest event had a magnitude of -3.5. Event locations are shown in Figure 3. We note that 200 events of magnitude $-3.5<\mathrm{M}<-0.5$ over an 8 year period is a very low level of seismicity. For comparison, at the In Salah CCS project, over 9,000 events were recorded in one year, with a maximum magnitude of 1.7 (Stork et al., 2015), while the Decatur pilot CCS project has seen events with a maximum magnitude of approximately 1.3 (Kaven et al., 2015).

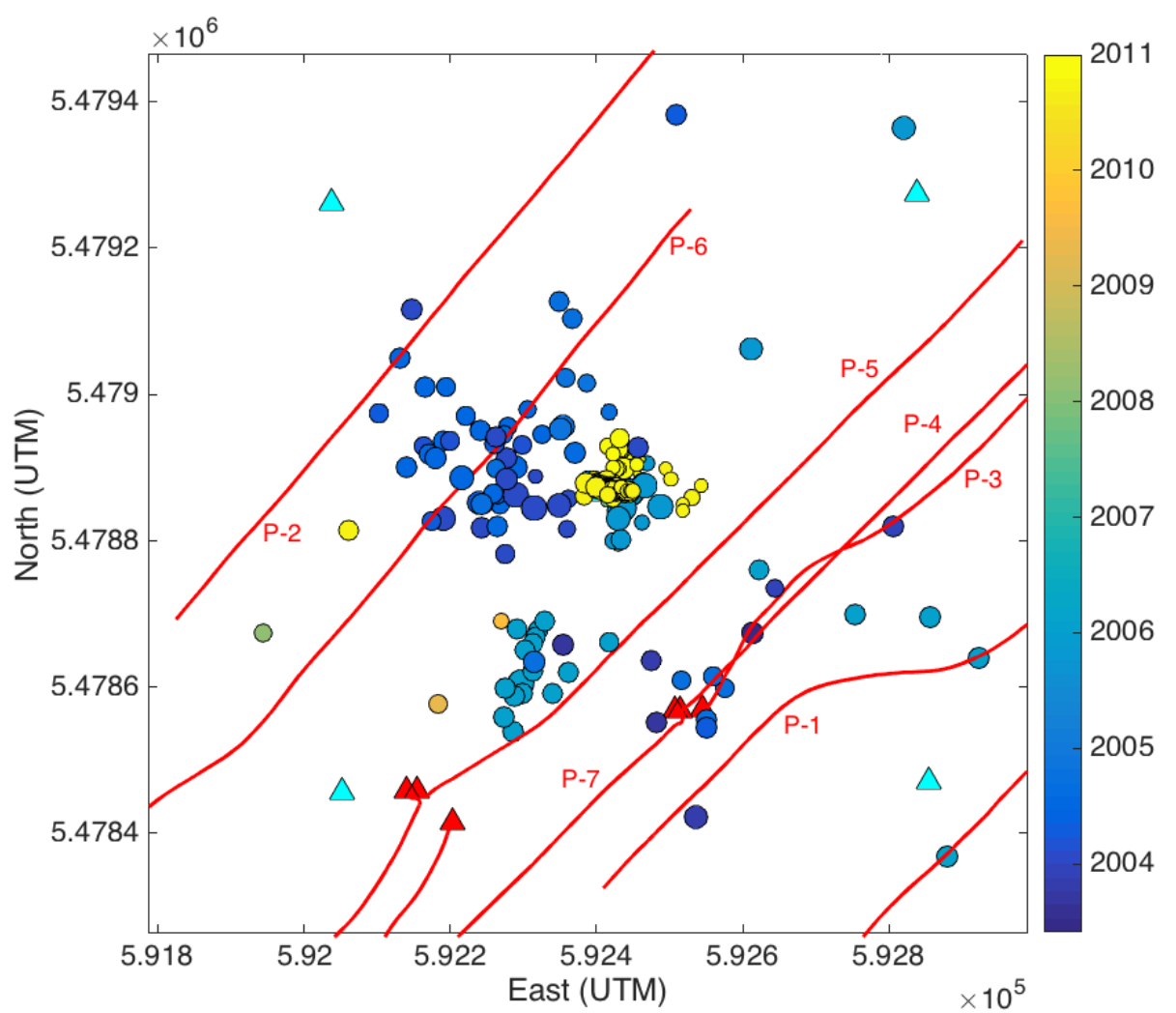

(a) 


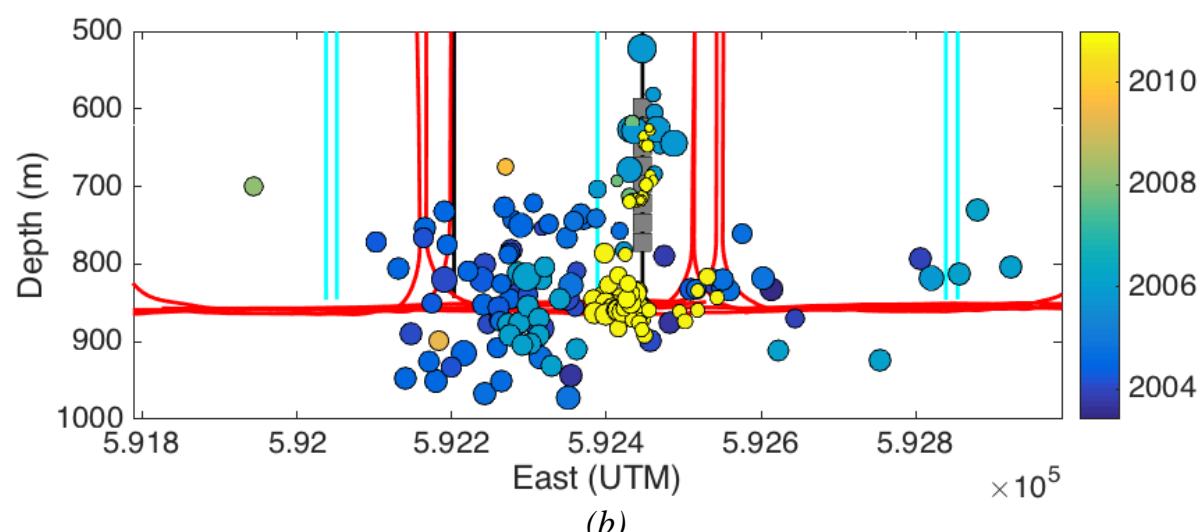

Figure 3: Map (a) and cross section (b) of microseismic event locations. Wells are depicted as per Figure 1. Microseismic events are coloured by occurrence date, and the size of the marker indicated event magnitudes (which range from -3.5 to -0.5 ).

There is a notable degree of temporal clustering in the recorded events. For long periods of time no seismicity is detected, interspersed with days and/or weeks where tens of events are recorded over a short period of time. It is not clear what causes this clustering to happen.

In the time between array installation in August 2003 and the start of injection in well I-1, 8 events were recorded by the array. These events were all located to the SE of the injection well, near to production wells P-3 - P-5. This indicates that oil production from the field was capable of triggering microseismicity even prior to the onset of $\mathrm{CO}_{2}$ injection.

15 events were detected within 2 days of the start of injection in well I-1. These events were primarily located around the production well to the northwest of the injection well, P-6, and in between this well and the injector. A further 45 microseismic events were recorded over the spring and summer of 2004, the majority of which were located to the northwest of I-1, with a few events recorded to the SE, in the same area as the events detected prior to injection (near wells P-3 - P-5).

The monitoring array was disabled from November 2004 until October 2005. A further 18 events were recorded in October 2005. These events were located at a range of depths (900 $1500 \mathrm{~m}$ below surface) in close proximity to the monitoring well. The mechanism for these events remains unclear. A further 21 events were recorded in January 2006, and were mainly located to the southeast of the monitoring well, near to production well P-5. From 2006 until 2010 only a further 8 events were recorded. In 2010 however, the injection well I-1 was shut in and abandoned. During the month following shut-in, a further 92 events were recorded. All of these events were located in close proximity to the injection well, at reservoir depths.

In Figure 4 we investigate the shift in loci of events from the general production and injection period to when the injection well I-1 is shut in. To better represent the spatial distribution of 
the overall seismic moment released, we generate a grid in $\mathrm{x}-\mathrm{y}$ space, and for each discretized point $\vec{x}$, we compute a parameter to represent the cumulative moment released by nearby events, $M_{S U M}(\vec{x})$ :

$$
M_{S U M}(\vec{x})=\log _{10}\left(\sum_{i=1}^{n e} M o_{i} N\left(D_{i, \vec{x}} E_{i}\right)\right),
$$

where $M_{O}$ is the seismic moment released by event $i$, and $N$ is the normal distribution, where $D_{i, \vec{x}}$ is the distance between event $i$ and grid point $\vec{x}$, and $E_{i}$ is the lateral event location error for event $i$.

In Figure 4, we plot smoothed contours of $M_{S U M}$ (normalised by the maximum value in each case) for the events recorded between 2003 - 2009 (Figure 4a), and for the events recorded after well I-1 was shut in in late 2010 (Figure 4b). For the events between 2003 - 2009. There are two main focuses of moment release (high values of $M_{S U M}$ ). The largest is located in close proximity to the production well to the southeast (P-5), while the second is centred on the production well to the northwest (P-6), and extends towards the injection well (I-1). In contrast, the events in 2010 once I-1 has been shut in are very clearly focussed around the same well (Figure 4b).

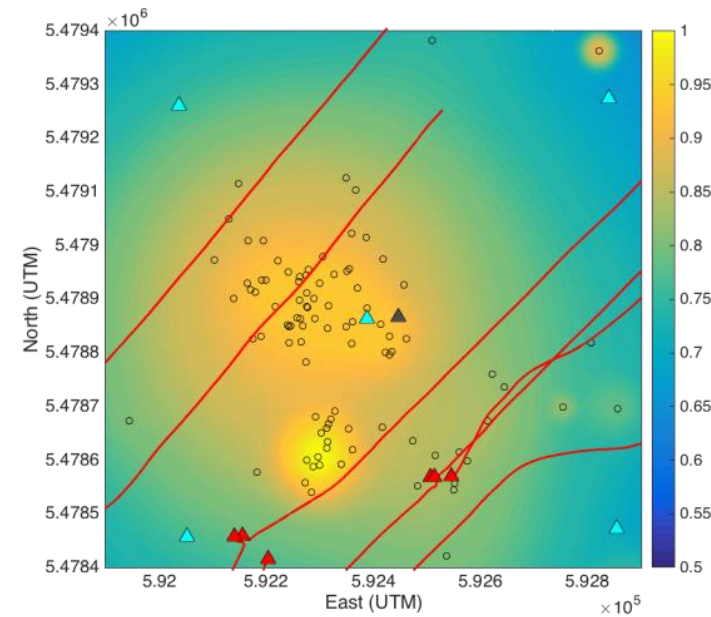

(a)

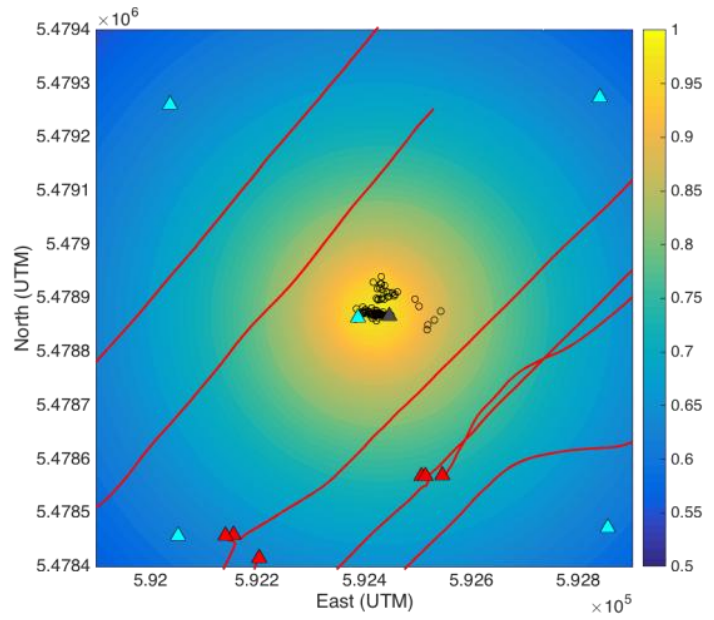

(b)

Figure 4: Smoothed contours of $M_{S U M}$ (equation 1), representing the spatial distribution of moment released, for the events recorded between $2003-2009$ (a), and after shut in of injection well I-1 in late 2010 (b). Black dots represent the event loci, while the injection and production wells are as per Figure 1.

In Figure 5 we investigate the different depths of these two event populations. This histogram shows that event depths during production and injection (2003 - 2009) are centred on the reservoir units, but a significant proportion (88\%) are located outside of the reservoir limits, 
either underneath or above the reservoir. In contrast, the majority (61\%) of events that occur after shut in of I-1 in 2010 are located within the reservoir interval.

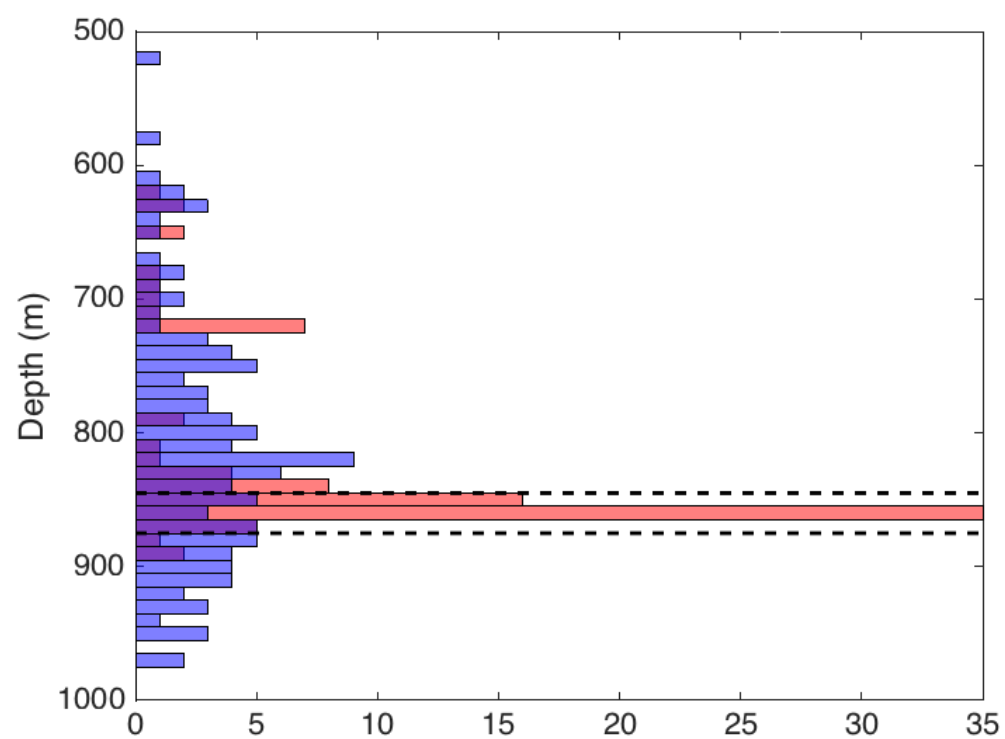

Figure 5: Histogram of event depths. Dashed black lines indicate the approximate reservoir depth. Blue bars represent events recorded from 2003 - 2009. The red bars indicate events recorded after the shut-in of the injection well in late 2010.

\section{INTERPRETATION OF MicroseisMic OBSERVATIONS}

Conventional theory pertaining to injection-induced seismicity is that pore pressure increases caused by injection act to reduce the normal stress, increasing the likelihood of failure on optimally oriented planes of weakness. As such, we would expect seismicity to correlate with areas of elevated pore pressure, and moreover the presence of microseismic activity would imply a hydraulic connection between injection wells and the loci of microseismic events. So events located in the overburden would imply a hydraulic connection through the reservoir and into the caprocks. This would be of obvious concern in terms of $\mathrm{CO}_{2}$ storage integrity, particularly if such events were located near to injection wells, where $\mathrm{CO}_{2}$ concentrations and pore pressures will be highest, and therefore the chance of leakage greater.

However, during injection and production at Weyburn, the focus of microseismic activity is at the production wells (Figure 4a), and in the under- and overburden as well as the reservoir (Figure 5). These are areas where the pore pressure is expected to be lower.

When the injection well is shut in, we would otherwise expect the reducing pore pressure to reduce microseismicity. Instead, we see a further burst of microseismicity. At this time, the events are located in close proximity to the shut-in well (Figure $4 \mathrm{~b}$ ), and mainly within the 
reservoir unit (Figure 5). These observations suggest that microseismicity at Weyburn is not driven directly by increasing pore pressures in the reservoir.

An alternative potential cause of microseismicity is from the geomechanical impacts of both injection and production from the reservoir. Stress can be transferred through the solid rock frame, leading to changes in both normal and shear stresses acting on planes of weakness, resulting in microseismicity (e.g., Verdon et al., 2015b). Importantly, these stress changes can be transferred into the rocks over- and underlying the reservoir (e.g., Segura et al., 2011), leading to microseismicity in the overburden even where there is no hydraulic connection (and therefore no $\mathrm{CO}_{2}$ leakage) into these rocks. This type of mechanism was first suggested by Segall (1989).

Verdon et al. (2011) constructed a coupled fluid-flow/finite element geomechanical model for the microseismic monitoring region of the Weyburn oilfield. A commercial reservoir flow model was used to simulate pore pressure changes caused by production and injection. These pore pressure changes are passed to a geomechanical model to simulate how the changes in pore pressure lead to stress changes in and around the reservoir.

The model was a simplified representation of the setup at Weyburn, with three vertical $\mathrm{CO}_{2}$ injection wells situated in between 4 horizontal oil production wells. Initially, the production wells were switched on without injection, to simulate the initial stages of unsupported production at Weyburn. At a later stage, the injection wells were switched on.

The coupled geomechanical model provides a map of stress as a function of time. In order to simulate induced microseismicity, Verdon et al. (2011) computed changes in the fracture potential, $f_{p}$, which describes how close the stress state is to the Mohr-Coulomb failure criteria. The higher the fracture potential, the more likely it is that a microseismic event will occur. The absolute value of $f_{p}$ will be determined primarily by the in situ tectonic stresses, and in particular the relative difference between the maximum and minimum principle stresses, and this will determine the maximum shear stress. However, Verdon et al. (2011) were particularly interested in the modelled changes in $f_{p}$ through time, as this would indicate the areas of the reservoir where fracturing, and therefore microseismicity, would be more likely to occur as a result of injection and/or production.

In their model, Verdon et al. (2011) found that a softer-than-expected reservoir unit promoted stress transfer into the surrounding under- and overburden rocks (such as that described by Segura et al., 2011). The result of this stress change was to increase $f_{p}$ in the rocks around the 
production wells, and especially in the overburden above the production wells, while $f_{p}$ in the rocks around the injection wells, where pore pressures were highest, was reduced slightly.

The areas of elevated $f_{p}$ modelled by Verdon et al. (2011) correspond to the areas where most microseismicity was observed at Weyburn, i.e., near to and in the overburden above the horizontal production wells. This also explains why microseismicity might occur after shut-in of the injection well: as pore pressure reduces after shut-in, $f_{p}$ actually increases slightly.

When considered within the framework of microseismicity induced solely by pore pressure increases, the microseismic observations at Weyburn are counter-intuitive. However, the Weyburn oilfield has a long and complex history of both fluid production and injection. It is therefore not surprising that the observed geomechanical effects cannot be accounted for with a simple pore-pressure-increase type framework. Instead, when the full geomechanical response to both production and injection are considered, microseismic events occur in areas where shear stresses are increasing in response to stress transfer through both the reservoir rocks, but also the rocks in the under- and overburden as well.

The model produced by Verdon et al. (2011) is informative with respect to storage integrity. There is no evidence from other geophysical measurements that substantial amounts of $\mathrm{CO}_{2}$ have leaked from the reservoir into the overburden. However, a number of microseismic events are located in the overburden. The Verdon et al. (2011) model has no hydraulic communication between reservoir and overburden - all of the injected $\mathrm{CO}_{2}$ remains in the reservoir. Instead, stress is transferred through the rock frame, and this stress transfer is capable of producing the observed patterns of microseismicity.

\section{USING MicroseISMICITY TO FoRECAST INDUCED SEISMICITY}

A number of recent studies have studied the statistics of populations of induced events to assess the likelihood of larger seismic events being triggered (e.g. Shapiro et al., 2011; Hallo et al., 2014; McGarr, 2014; Verdon et al., 2015). In this section we consider the events recorded at Weyburn in a similar manner.

\subsection{Gutenberg-Richter relationship}

The Gutenberg-Richter relationship describes the number of events recorded as a function of the event magnitude. For most earthquake catalogues, the number of events, $N$, larger than a given magnitude, $M$, is described by the relationship

$$
\log _{10} N=a-b M
$$


where $a$ and $b$ are constants to be determined. The constant $b$ is of particular interest, and is often referred to as the ' $b$ ' value. For most tectonic earthquake populations, $b$ is found to be equal to 1 (Frohlich and Davis, 1993). However, in certain situations, higher $b$-values have been observed, most notably where fluids play a significant role in the deformation (e.g., Wyss et al., 1997). This is particularly true for microseismic monitoring of hydraulic fracture stimulation, where $b$-values of 2 or more are common (e.g., Verdon et al., 2013b). As such, $b$ values can be used to help better understand the style deformation that is producing induced seismicity.

Figure 6 shows the frequency-magnitude distribution for events recorded at Weyburn, calculated using the method described by Verdon (2013). The best-fit $b$-value is 1.1 , very close to the value typically observed for tectonic events of 1 . A $b$-value of 1 is consistent with the interpretation discussed in the previous section, where Verdon et al. (2011) concluded that the events have not been directly triggered by the pore pressure increase associated with injection. Instead, the transfer of stress through the rock frame drives the microseismicity. We can make a contrast between this situation and that of the In Salah CCS site, where seismicity is driven directly by pore-pressure increases, and the $b$-value is observed to be larger than 2 (Stork et al., 2015).

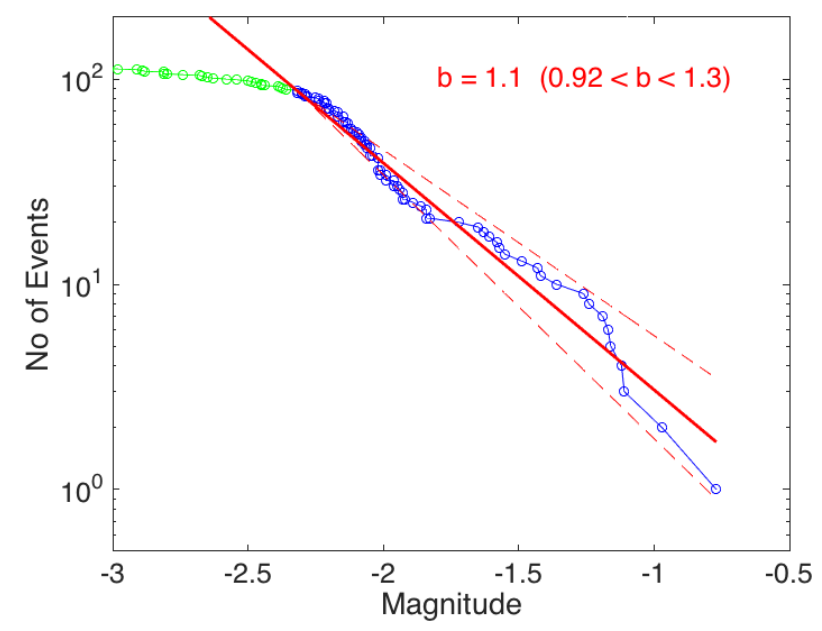

Figure 6: Frequency-magnitude distribution for microseismic events. A b-value close to 1 is recorded. Blue dots show events used in the analysis, green dots show events below the detection threshold, while the red line shows the G-R fit to the data, and dashed lines show the confidence interval.

\subsection{Seismic Efficiency and Maximum Magnitude}

From observations of numerous cases of injection-induced seismicity, McGarr (2014) defined a relationship between the seismic moment released by the largest event, $M_{O M A X}$ and the total change in volume, $\Delta V$, injected into or produced from a reservoir, 


$$
M_{O M A X}=G \Delta V
$$

where $G$ is the rock shear modulus.

The McGarr (2014) relationship describes the worst-case scenario, where all of the deformation induced by injection/production is released seismically, and all of the seismic moment is released as a single large event. In reality, much of the deformation is released aseismically, while energy that is released seismically may be released as a series of small events, rather than a single large event: this distribution is determined by the $b$-value, as discussed above, where a $b$-value of 0 implies all of the seismic moment is released as a single event.

Hallo et al. (2014) therefore modified the McGarr (2014) relationship, such that only a portion of the injected (or produced) volume is released seismically. This factor is referred to as the seismic efficiency, $S_{E F F}$, which is computed as $S_{E F F}=\Sigma M_{O} / G \Delta V$, where $\Sigma M_{O}$ is the cumulative seismic moment released. The largest event magnitude, $M_{M A X}$, for a given injection or production volume can then be written as

$$
M_{M A X}=\frac{2}{3}\left(\log _{10}\left(\frac{S_{E F F} G V\left(\frac{3}{2} b\right)}{b \cdot 10^{9.1}}\right)+\log _{10}\left(\begin{array}{ll}
10^{b} & 10^{b}
\end{array}\right)\right),
$$

where $\delta$ is defined by Hallo et al. (2014).

The advantage of this approach is that both $S_{E F F}$ and $b$ can be measured continually throughout injection, allowing operators to make estimates of $M_{M A X}$ for a given future injection volume. Here we demonstrate this process for the Weyburn microseismic data.

To compute $S_{E F F}$, a volume change is needed to correlate with cumulative seismic moment released. Typically, most projects either only inject or only produce fluids from the reservoir, and as such the volume change is easily computed as the cumulative injected/produced volume. However, at Weyburn, fluids are both injected and produced in close proximity to each other. The appropriate volume in this case is therefore less well defined. Therefore, in the following we consider two possibilities: firstly that $\Delta V$ is simply the cumulative volume of fluid injected through well $\mathrm{I}-1$; and secondly that $\Delta V$ is the net change in volume considering both fluid injected through well I-1 and fluid extracted from the 7 wells surrounding the microseismic monitoring area $(\mathrm{P}-1-\mathrm{P}-7)$. 
Figure 7 shows cumulative volume change and cumulative seismic moment released under these two scenarios. Where fluid injection/production is directly triggering seismicity, a close correlation between $\Delta V$ and $\Sigma M_{O}$ is expected (see Figure 1b of Shapiro et al., 2011, for an example). At Weyburn, there is not an obvious correlation between $\Delta V$ and $\Sigma M_{O}$, regardless of whether we consider injected volume or net volume change. This lack of close correlation between injected volume and cumulative moment released is further corroboration of the interpretations made in Section 3, namely that microseismicity is caused by stress transfer through the rock frame, and is not being driven directly by pore pressure changes induced by injection.

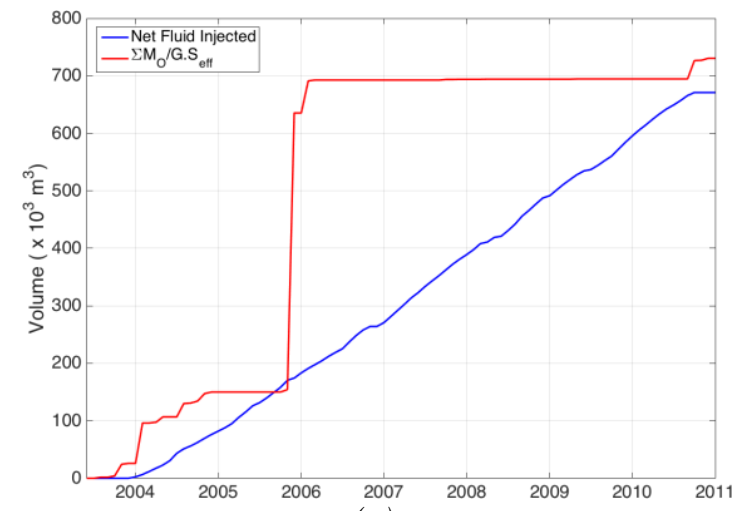

(a)

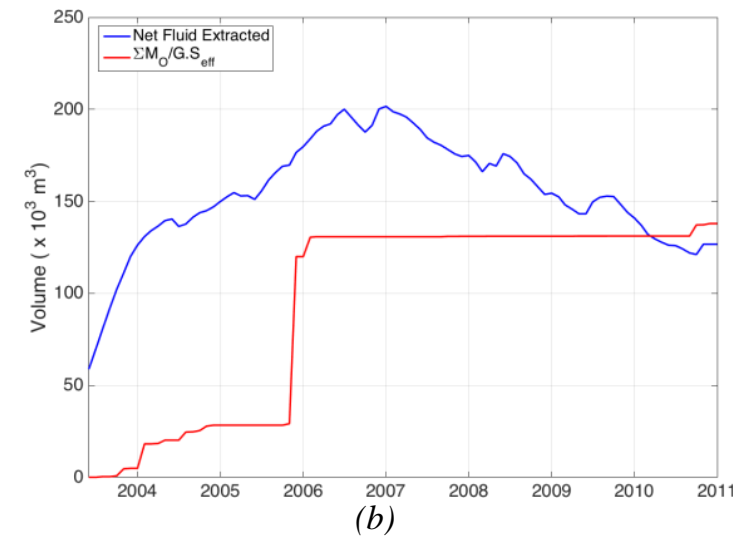

(b)

Figure 7: Cumulative volume change and cumulative seismic moment released (scaled by the appropriate seismic efficiency) for two scenarios, (a) considering only fluid injection through I-1, and (b) net volume of fluid extracted considering production from wells $P-1-P-7$ and injection into I-1.

Figure 8 shows forecast values for $M_{M A X}$ following equation 4 . In the lower panels of Figure 8 we update $b$ and $S_{E F F}$ based on the microseismic data recorded up until a given time. We then use these values to compute an expected value for $M_{M A X}$ for the total volume change $\Delta V$ at this time (injection only in Figure 8a, net volume change in Figure 8b). We note that the $b$ value remains close to 1 throughout the monitoring period. $S_{E F F}$ remains very low, at a value of less than $2.6 \times 10^{-7}$ when considering injection only, and less than $3.1 \times 10^{-7}$ when considering net volume change. As such, the forecast values for $M_{M A X}$ never exceeds magnitude 0.0 in either case. As such, as long as $S_{E F F}$ and $b$ remain at these levels during operations, we do not expect $\mathrm{CO}_{2}$ injection at Weyburn to trigger felt seismicity. Continued microseismic monitoring can warn if these values begin to change, which might represent a previously inactive fault becoming active, for example. 

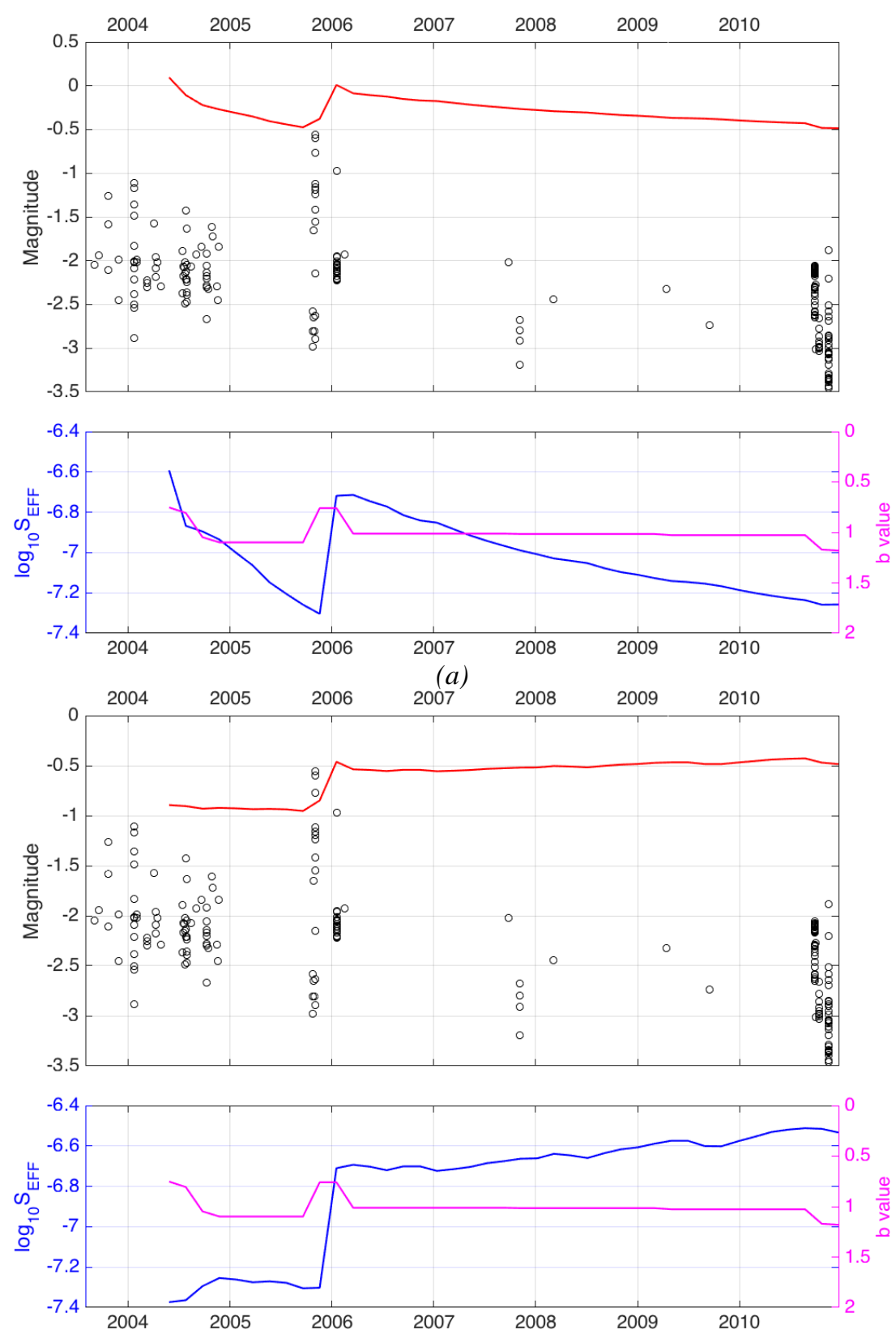

(b)

Figure 8: Using equation 4 to forecast $M_{M A X}$ based on the observed microseismic data. In the lower panels of each plot, $S_{E F F}$ and $b$ are continually updated. In the upper panels, equation 4 is used to update the forecast $M_{M A X}$ (red line). Also shown are the observed magnitudes (black dots). The forecast $M_{M A X}$ does a good job of matching observations at Weyburn, suggesting that larger, felt events are unlikely. As per Figure 7, we consider two scenarios, (a) considering only fluid injection through I-1, and $(b)$ net volume of fluid extracted considering production from wells $P-1-P-7$ and injection into I1 .

\subsection{Seismogenic Index}

An alternative measure of the seismicity induced by injection is the seismogenic index. Shapiro et al. (2010) define the seismogenic index, $\Sigma$, to characterise the number of events of 
a given magnitude generated by injection. They observe that $N$ at time $t$ is a function of the volume change at this time and $\Sigma$ :

$$
\log _{10} N=\log _{10} \Delta V(t)-b M+\Sigma .
$$

$\Sigma$ should remain constant through time, regardless of injection rate, or the chosen value of $M$. In Figure 9a we plot the variation in $\Sigma$ through time for the Weyburn events, noting that for most of the study period, $-6.5<\Sigma<-5.5$, with a mean of -6 . Dinske and Shapiro (2013) catalogue $\Sigma$ for a range of injection projects (geothermal, wastewater disposal, shale gas hydraulic fracturing), including those that have triggered felt seismicity, finding that measured seismogenic indices range from $-9.5<\Sigma<0.5$. The value of $\Sigma$ observed at Weyburn is towards the lower end of the range described by Dinske and Shapiro (only hydraulic stimulation at Cotton Valley and in the Barnett Shale have lower values for 2 ).

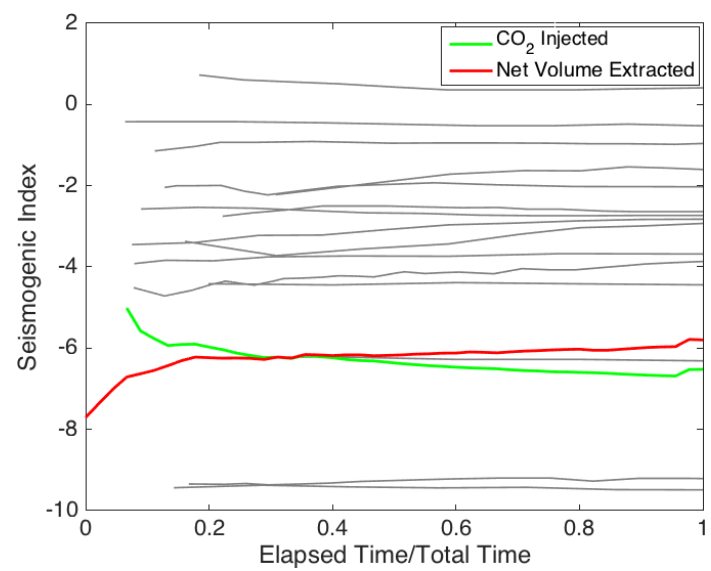

(a)

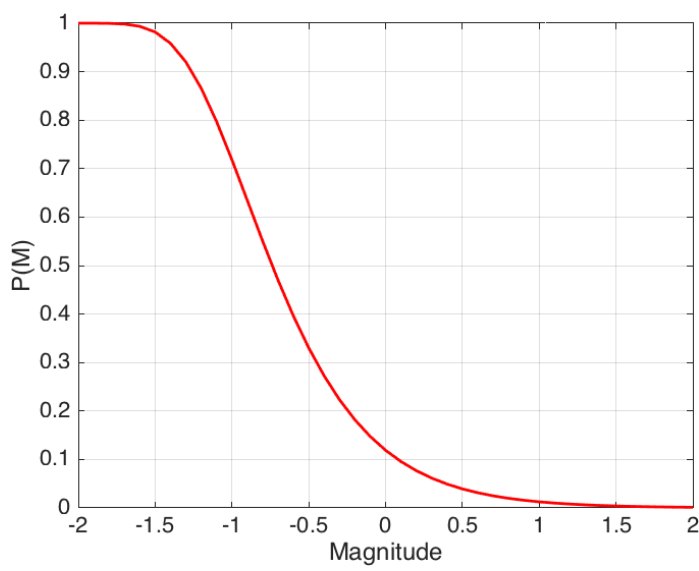

(b)

Figure 9: Panel (a) shows the seismogenic index measured for the microseismic events recorded at Weyburn, using $\mathrm{CO}_{2}$ injected (green) and net volume change (red) as the volumes to which seismic moment is correlated. The grey lines correspond to the values computed by Dinske and Shapiro (2013) for a range of sites. Panel (b) shows the forecast magnitude probabilities based on a $\Sigma$ value of -6 . Values for 5of approximately -6 are towards the low end of the range observed by Dinske and Shapiro (2013), implying a low risk of felt seismicity at Weyburn.

Shapiro et al. (2010) show how $\Sigma$ can be used to estimate the probability that an event of a given magnitude is induced. The probability that a given magnitude will be exceeded, $P(M)$ can be computed from the seismogenic index and the $b$ value as:

$$
P(M)=1 \quad \exp \left(\quad V .10^{b M}\right)
$$


This probability as a function of magnitude is shown in Figure 9b, and indicates a $12 \%$ probability that an event larger than magnitude 0.0 will occur, and less than $1 \%$ chance that an event larger than magnitude 1.0 will occur. We conclude that the seismogenic index measured here provides a further indication that at present there is a low risk of triggering felt seismicity at Weyburn.

\section{CONCLUSIONS}

In this paper we present a reanalysis of the microseismic events recorded during oil production and $\mathrm{CO}_{2}$ injection into the Phase $1 \mathrm{~B}$ portion of the Weyburn oilfield. The most notable feature of the microseismic observations is that they do not match with conventional ideas about injection-induced seismicity, where high pore pressures reduce the effective normal stress, leading to seismicity in areas with high pore pressure. Instead, events are primarily located adjacent to production wells, where pore pressures might be expected to be lower, and in the under- and overburdens above/below these wells. Microseismicity does occur near to the injection well, but only once this well has been shut in and pore pressures are falling.

However, these observations can be understood once the full geomechanical response to both production and injection is considered, with stresses being transferred through the rock frame, both in the reservoir and through the under- and overburden. On this understanding, events in the overburden do not imply a hydraulic connection, and therefore do not suggest a risk of leakage.

The re-analysis of the microseismic events presented here corroborates the geomechanical interpretation presented by Verdon et al. (2011). The Gutenberg-Richter $b$-value is observed to be close to 1 , similar to values for tectonic settings, whereas higher $b$-values are commonly observed in situations where seismicity is directly driven by fluid and pore pressure changes (such as at volcanoes, during hydraulic fracturing, or in other injection-induced seismicity case studies). Furthermore, there is no obvious correlation between fluid volume changes and the rate of seismic moment release, as is often observed when fluid injection is driving seismicity directly.

Finally, we use two methods to make estimates about the possibility of $\mathrm{CO}_{2}$ injection leading to induced seismic events of sufficient magnitude to be of concern to local populations. Using both the seismic efficiency (as described by Hallo et al., 2014), and the seismogenic index (as described by Shapiro et al., 2010), we find that, based on the observed microseismicity to date, the probability of inducing an event with magnitude greater than 1.0 is very remote. 
Continued monitoring at Weyburn will allow operators to quickly establish if this were to change - for instance if injection began to re-activate a previously inactive fault. However, given that injection has now proceeded at Weyburn for over 15 years without any felt seismicity, this scenario appears to be very unlikely.

\section{Acknowledgements}

The author would like to thank the US Department of Energy, and the Petroleum Technology Research Centre of Canada, for funding this research. James Verdon's Research Fellowship at the University of Bristol is supported by the British Geological Survey.

\section{References}

Dinske C. and Shapiro S.A., 2013. Seismotectonic state of reservoirs inferred from magnitude distributions of fluid-induced seismicity: Journal of Seismology 17, 13-25.

Ellsworth W.L., 2013. Injection-induced earthquakes: Science 341, 1225942.

Frohlich C. and Davis S.C., 1993. Teleseismic $b$ values; or, much ado about 1.0: Journal of Geophysical Research 98, 631-644.

Hallo M., Oprsal I., Eisner L., Ali M.Y., 2014. Prediction of magnitude of the largest potentially induced seismic event: Journal of Seismology 18, 421-431.

Hitchon B., 2012. Best practices for validating $\mathrm{CO}_{2}$ geological storage: observations and guidance from the IEAGHG Weyburn-Midale $\mathrm{CO}_{2}$ monitoring and storage project. Geoscience Publishing, Sherwood Park, Alberta, Canada.

Kaven J.O., Hickman S.H., McGarr A.F., Ellsworth W.L., 2015. Surface monitoring of microseismicity at the Decatur, Illinois, $\mathrm{CO}_{2}$ sequestration demonstration site: Seismological Research Letters 86, 1096-1101.

Keranen K.M., Weingarten M., Abers G.A., Bekins B.A., Ge S., 2014. Sharp increase in central Oklahoma seismicity since 2008 induced by massive wastewater injection: Science 345, 448-451.

Maxwell S.C., White D.J., Fabriol H., 2005. Passive seismic imaging of $\mathrm{CO}_{2}$ sequestration at Weyburn: $74^{\text {th }}$ SEG Annual Meeting, Expanded Abstracts.

McGarr A., 2014. Maximum magnitude earthquakes induced by fluid injection: Journal of Geophysical Research 119, 1008-1019.

Segall P., 1989. Earthquakes triggered by fluid extraction: Geology 17, 942-946.

Segura J.M., Fisher Q.J., Crook A.J.L., Dutko M., Yu J.G., Skachkov S., Angus D.A., Verdon J.P., Kendall J-M., 2011. Reservoir stress path characterization and its implications for fluid-flow production simulations: Petroleum Geoscience 17, 335-344.

Shapiro S.A., Dinske C., Langenbruch C., Wenzel F., 2010. Seismogenic index and magnitude probability of earthquakes induced during reservoir fluid stimulations: The Leading Edge 29, 304-308.

Shapiro S.A., Krüger O.S., Dinske C., Langenbruch C., 2011. Magnitudes of induced earthquakes and geometric scales of fluid-stimulated rock volumes: Geophysics 76, WC55-WC63.

Stork A.L., Verdon J.P., Kendall J-M., 2015. Assessing the microseismic response at the In Salah Carbon Capture and Storage (CCS) site with a single three-component geophone: International Journal of Greenhouse Gas Control 32, 159-171.

Verdon, J.P., 2013. Fractal dimension of microseismic events via the two-point correlation dimension, and its correlation with $\mathrm{b}$ values: $4^{\text {th }}$ EAGE Passive Seismic Workshop, Amsterdam. 
Verdon J.P., Kendall J-M., White D.J., Angus D.A., 2011. Linking microseismic event observations with geomechanical models to minimise the risks of storing $\mathrm{CO}_{2}$ in geological formations: Earth and Planetary Science Letters 305, 143-152.

Verdon J.P., Kendall J-M., Stork A.L., Chadwick R.A., White D.J., Bissell R.C., 2013a. Comparison of geomechanical deformation induced by megaton-scale $\mathrm{CO}_{2}$ storage at Sleipner, Weyburn, and In Salah: Proceedings of the National Academy of Sciences 110, E2762-E2771.

Verdon J.P., Wuestefeld A., Rutledge J.T., Main I.G., Kendall J-M., 2013b. Correlation between spatial and magnitude distributions of microearthquakes during hydraulic fracture stimulation: $75^{\text {th }}$ EAGE Annual Meeting, London

Verdon J.P., Werner M.J., Stork A.L., Kendall J-M., 2015a. Real time forecasting of maximum expected induced seismicity: $77^{\text {th }}$ EAGE Annual Meeting, Madrid.

Verdon J.P., Stork A.L., Bissell R.C., Bond C.E., Werner M.J., 2015b. Simulation of seismic events induced by $\mathrm{CO}_{2}$ injection at In Salah, Algeria: Earth and Planetary Science Letters 426, 118-129.

Worth K., White D., Chalaturnyk R., Sorensen J., Hawkes C., Rostron B., Johnson J., Young A. 2014. Aquistore project measurement, monitoring and verification: From concept to $\mathrm{CO}_{2}$ injection: Energy Procedia 63, 3202-3208.

Wyss M., Shimazaki K., Wiemer S., 1997. Mapping active magma chambers by $b$ values beneath the off-Ito volcano, Japan: Journal of Geophysical Research 102, 20413-20422.

Zoback M.D. and Gorelick S.M., 2012. Earthquake triggering and large-scale geologic storage of carbon dioxide: Proceedings of the National Academy of Sciences 109, 1016410168. 